\title{
The Viability of a Voting System that Allocates Parliamentary Seats According to Life Expectancy: An analysis using OLG models ${ }^{1}$
}

\author{
Kazumasa Oguro \\ Associate Professor, Institute of Economic Research \\ Hitotsubashi University \\ Ryo Ishida \\ Visiting Scholar, Policy Research Institute \\ Ministry of Finance
}

\begin{abstract}
This paper constructs an overlapping generations model in order to demonstrate how political intervention and interaction in the working and retired generations affect the allocation rate in future growth-stimulating public investment and the public pension. It also analyzes the possibility of moving to a voting system that allocates parliamentary seats according to life expectancy. The presented results suggest the following three main findings. Firstly, the voting system is important when population demographics change. Declining birthrates and an aging population may shorten the temporal perspective for policymaking over time. Any theoretical transition from the current voting system to a voting system that allocates parliamentary seats according to life expectancy would thus lengthen the temporal perspective for policymaking, potentially increasing the public investment rate and improving the utilities of the working and future generations. Secondly, when age-based voting turnout disparity is high, the shift from the current voting system to one based on life expectancy and region or life expectancy and age is possible. Thirdly, if both transitions from the current system are possible, moving to the latter would offer greater possibility for increasing the utilities of the working generation and future generations than moving to the former.
\end{abstract}

JEL classification codes: D90, H50, H60, J18, O20

Keywords: Public investment, Public pension, OLG model, Generational-based constituency bloc,

Demeny voting system, Life expectancy

\section{Introduction}

During periods when modern democracy was being established, such as $17^{\text {th }}$ century England on the back of the Puritan Revolution and following the French and American Revolutions of the $18^{\text {th }}$

\footnotetext{
${ }^{1}$ Kazumasa Oguro (Institute of Economic Research, Hitotsubashi University, 2-1, Naka, Kunitachi, Tokyo, 186-8603, JAPAN. tel: +81-42-580-8312, e-mail: ZVU07057@nifty.com) and Ryo Ishida (corresponding author, 3-1-1, Kasumigaseki, Chiyoda-Ku, Tokyo 100-8940, JAPAN. Tel: +81-3-3581-4111, FAX: +81-3-5251-2113, e-mail: rrishida112358@gmail.com). We would like to express our gratitude to the many people who advised us during the writing of the first draft of this paper, particularly Prof. Akira Yakita, Nagoya City Univ.; Prof. Shinji Yamashige, Hitotsubashi Univ.; Prof. Toru Nakazato, Sophia Univ.; and Prof. Jun Iritani, Fukuyama Univ. In addition, we would like to note that Kazumasa Oguro received a research grant from the Grants-in-Aid for Scientific Research (Grant no. 23730270). The views expressed herein are those of the authors, and do not necessarily reflect the opinions of the organizations to which the authors belong. The responsibility for all errors is solely that of the authors.
} 
century, newly democratic countries tended to experience favorable and steady population growth (notwithstanding exceptional factors such as war). Likewise, but to a far greater degree, the human race experienced a population explosion during the $20^{\text {th }}$ century to reach the highest level of population in the history of humankind. Because the younger generation constituted a high percentage of the electorate in such periods, a long temporal perspective was applied to policymaking regardless of whether individuals were self-serving or behaved according to the lifecycle hypothesis. In this case, the length of the temporal perspective, based on the assumption of a high percentage of younger generation voters, would thus play an important role in the effective intertemporal allocation of economic resources.

However, the reverse may be considered true in the $21^{\text {st }}$ century. As many advanced countries face rapidly declining birthrates and aging populations, this assumption is beginning to lose validity. Japanese society, in particular, is witnessing an unprecedented period of rapid aging in modern times. This combination of a rapidly declining birthrate and aging population suggests that most advanced countries can expect the electorate to comprise a high percentage of retired voters. Therefore, assuming individuals are self-serving and behave according to the lifecycle hypothesis, the temporal perspective applied to policymaking can be expected to be even shorter.

This paper constructs an overlapping generations (OLG) model in order to demonstrate how the political dynamics between the working and retired generations affect the allocation rate in future growth-stimulating public investment (e.g., science and technology R\&D) and the public pension. It also analyzes the possibility of moving to a voting system that allocates parliamentary seats according to life expectancy (life expectancy-based voting system hereafter) based around the findings of Takeuchi (2011).

When policymakers decide between allocating government funds to public investment, which promotes future growth and benefits the younger and future generations, and the public pension, which singularly benefits the retired generation, greater political emphasis is often placed on allocations to the latter. For example, the studies by Tabellini (1990) and Breyer and Craig (1997) 
confirmed the positive correlation between average voter age and government transfer into the public pension (as a percentage of GDP). The relationship between policy making and budget deficit has also been confirmed by many studies, both theoretically and empirically, since the 1990s (e.g., Alesina et al., 1998; Persson and Tabellini, 2000; Shi and Svensson, 2006). Further, Cukierman and Meltzer (1989) pointed out the existence of intergenerational exploitation, ${ }^{2}$ which occurs when a generation is non-altruistic and burdens future generations with extra tax by cutting tax rates and issuing government bonds. Indeed, as the temporal perspective used in government decision-making condenses, the exploitation between generations accelerates. This phenomenon is inferred by, for example, Silke (2004), which stated that gerontocracy has a risk of further expansion of pension expenditure, by which the exploitation between generations would be reinforced; or by Hirazawa et al. (2010), which stated that population aging results in an increase in the contribution rate with respect to a pay-as-you-go pension system.

This phenomenon represents a failure of democracy and calls for a debate of corrective measures, with the voting system central to the solution. As Ortega (1961: 121) described, "The health of democracies, of whatever type and range, depends on a wretched technical detail —electoral procedure. All the rest is secondary. If the regime of the elections is successful, if it is in accordance with reality, all goes well; if not, though the rest progresses beautifully, all goes wrong."

The discussion of voting systems most often focuses on a comparison of Mill's (1861) "proportional representation" and Bagehot's (1867) "majority representation" or on the debate about the vote-value disparity that exists between urban and regional constituency blocs. However, given the accelerating trend of low birthrates and aging populations, the most relevant topic for discussion should rather be a voting system that extends the temporal perception applied to policymaking.

\footnotetext{
${ }^{2}$ For example, in addition to studies of political economics, please note the proven relationships between a politician's re-election incentive or a change of administration and political finance cycles (e.g., Rogoff, 1990; Kneebone and McKenzie, 2001; Foucault et al., 2008) and between the potential for a change of administration and strategic incentives (e.g., Persson and Svensson, 1989; Tabellini and Alesina, 1990; Crain and Tollison, 1993). Note also the common pool problem (e.g., Alesina and Drazen, 1991; Ihori and Itaya, 2001).
} 
In this vein, Aoki and Vaithianathan (2009) and Oguro et al. (2012) analyzed the efficacy and potential for implementing the Demeny voting system proposed by Demeny (1986). This system grants voting rights to children, allowing each parent (or guardian) to cast a proxy vote for each dependent child. Similarly, Ihori and Doi (1998) proposed their so-called "age-based constituency bloc" system that allocates seats in parliament to each generation based on the eligible voter population structure by age group, rather than according to regional constituency blocs. For instance, one could categorize eligible voters into three generations: the young constituency of people in their $20 \mathrm{~s}$ and $30 \mathrm{~s}$, the middle-aged constituency of those in their 40s and 50s, and the older constituency of individuals 60 years old and over.

Takeuchi (2011) recently expanded Ihori and Doi's (1998) suggestion by proposing a voting system based on allocating parliamentary seats according to life expectancy as well as to age. For example, if the lifetime of each voter is 100 years, then a 30 -year-old voter in the young constituency would have a 70-year life expectancy, a 50-year-old voter in the middle-aged constituency would have a 50-year life expectancy, and a 70-year-old voter in the elderly constituency would have a 30-year life expectancy. In this case, the number of parliamentary seats elected by the young constituency would be 1.2 times greater than that of the middle-aged constituency and 2.3 times greater than that of the elderly constituency. ${ }^{3}$ Although this system would seem to cause vote-value disparity, it is theoretically interesting as it maintains vote-value equality throughout the entire lifespan of a voter, excluding the transition period.

The remainder of this paper is structured as follows. Section 2 compares the current voting system, Demeny voting system, and aged-based voting system from the perspective of the equality of electoral rights (i.e., "calculated value equality" and "vote-value equality") and re-examines the contents of the life expectancy-based voting system. Based on these results, Section 3 constructs an

\footnotetext{
3 According to Takeuchi (2011), under such a system life expectancy is assumed to equal "current average lifespan less current age." For the purpose of this study, however, we define life expectancy as "limited life expectancy," namely "limited lifespan less current age," for two reasons. Firstly, when mixing a generation that features a short average lifespan and with one that features a long average lifespan, the average life expectancy for people of the same age may differ based on their generation, which means that vote-value equality may not hold throughout a lifetime. Secondly, limited lifespan defined biologically is generally considered to be uniform, namely uninfluenced by either generation or time period.
} 
OLG model in order to demonstrate how political intervention and interaction in the working and retired generations affect the allocation rate in future growth-stimulating public investment and the public pension. Section 4 analyzes the theoretical possibility of moving to a life expectancy-based voting system, while Section 5 summarizes and provides future topics for discussion.

\section{Re-examination of a life expectancy-based voting system}

It is necessary to re-examine the equality of electoral rights when viewing democracy from a generational perspective. As Ashibe (2000) pointed out, "From the $19^{\text {th }}$ century through the first half of the $20^{\text {th }}$ century, equality of electoral rights primarily indicated the prohibition of plural voting (equality in the number of votes, or 'calculated value' equality). This is the 'one man, one vote' principle. However, as the privilege and significance of voting rights became more prominent issues, the meaning began to infer the equality of influence (equality of voting outcome value) on the results of elections based on individual votes." Therefore, the equality of voting rights has two aspects: calculated value equality and vote-value equality.

The former consists of temporary equality and lifetime equality. Temporary equality can be described as the equality of the number of votes one can cast for each election. From this perspective, Demeny (1986) proposed extending voting rights to children. Lifetime equality, by contrast, indicates the equality of the total number of votes throughout an entire lifespan (i.e., a life expectancy-based voting system). Assuming a lifespan of 100 years, for a voter of $t$ years $(t=20$, $21, \ldots, 100)$, a voting system with (100-t) votes would not provide temporary equality but would provide lifetime equality. Additionally, by setting an endowed upper limit on the total number of votes throughout an entire lifespan, a voting system that enables individuals to cast multiple votes in each election within the endowment would satisfy lifetime equality but not temporary equality.

In the latter type, vote-value equality is heavily influenced by the electoral divisions of indirect democracy. ${ }^{4}$ For example, according to Article 4 of Japan's Public Offices Election Act, the House

\footnotetext{
4 In a democracy, Diet members are selected using two methods: direct democracy (a system in which final political
} 
of Representatives (Lower House) has 480 seats (300 for single-seat constituency blocs and 180 for proportional representation blocs) and the House of Councilors (Upper House) has 242 seats (146 for constituency blocs and 96 for proportional representation blocs). ${ }^{5}$ In this situation, vote-value disparity between urban and regional voters is caused by the proportional representation method in Lower House elections and "one vote districts" in Upper House elections as well as constituency bloc allocation. Vote-value disparity violates Article 14 of the Japanese constitution (e.g., the maximum vote-value disparity is approximately two in Lower House elections and five in Upper House elections ${ }^{6}$ ). Although resolving vote-value disparity, particularly concerning Parliament, is now under study, the declining birthrate and aging population introduces the additional issue of intergenerational vote-value equality, as discussed in the Introduction.

In order to clarify this issue, let us assume that there are five region-based constituency blocs (A, B, C, D, and E). Urban area A has 100 eligible voters (80 working generation and 20 retired generation) and one Diet seat, whereas each of the regional areas B, C, D, and E has 50 eligible voters (20 working generation and 30 retired generation) and one Diet seat. In this situation, the urban Diet member represents 100 voters, whereas regional Diet members represent 50 voters each,

decisions are made through direct voting by eligible voters according to constituency blocs without the use of representatives) and indirect democracy, which comprises two stages. In stage 1, representatives are selected in a vote by eligible voters according to constituency blocs, while in stage 2 , elected representatives then make final political decisions through a voting process. Direct democracy cannot be considered an ideal decision-making mechanism, nor can indirect democracy, as illustrated by Condorcet's voting paradox (Condorcet (1785)) and Arrow's general impossibility theorem (Arrow (1950)).

5 In Lower House elections, eligible voters have two opportunities to vote, namely once for individual candidates in single-seat constituencies and once for their political party under proportional representation. Diet seats are allocated among the 300 single-seat constituencies via a system in which each of the 47 Japanese prefectures are allotted one seat as an "extraordinary constituency," and the remaining 253 seats are allocated via the "proportional representation method" in proportion to population. In addition, the proportional representation election system recognizes double candidacy with the single-seat constituency system, as the binding list system enables voting for political parties in the 11 regional blocs. At the same time, in Upper House elections, voters have two opportunities to vote, namely once for individual candidates in constituencies and once for either a political party or an individual candidate in proportional representation blocs. Constituencies are determined by administrative divisions (four types of prefectures): five-person districts (Tokyo-to), three-person districts (one "fu" and four "ken"), two-person districts (one "do" and 10 "ken"), and one-person districts (29 "ken"). The 29 "ken" constituency blocs are, in effect, equivalent to single-seat constituencies. In proportional representation elections, the non-binding list system is applied, as voters select a political party or individual candidate in all blocs across the country, while double candidacy is not permitted in conjunction with constituency bloc elections.

${ }^{6}$ The three criteria used to gauge vote-value disparity vary according to what elected officials are expected to represent: (1) population (e.g., the US), (2) number of eligible voters (e.g., the UK, Japan), and (3) voter turnout (e.g., Germany). Gauging disparity based on eligible voters indicates that the vote value is the number of eligible voters per elected official. However, vote-value disparity corrections are most commonly implemented by either adjustments to Diet seat allocations (e.g., reallocate seats to limit the number of seats for constituency blocs with large disparities) or adjustments to constituency blocs (e.g., re-zoning or merging constituencies) (Miwa and Kawashima, 2008). 
creating a (twofold) vote-value disparity between areas. Further, as both generations behave in a self-serving manner, there is a high probability that the regional areas will elect Diet members whose politics favor the retired generation, which increases the possibility that political decisions made in the Diet will favor this population.

Even if urban area $\mathrm{A}$ is allotted two Diet seats as a corrective measure to reduce vote-value disparity, this does not reverse the high probability that regional areas will elect Diet members whose politics favor the retired generation. Therefore, the intergenerational problem described above remains unresolved. The simplest answer to this problem is replacing the current region-based constituency bloc allocation to a generation-based system (see Table 1).

Table 1: Calculated Value Equality and Vote-Value Equality

\begin{tabular}{|c|c|c|}
\hline Calculated Value Equality & Region-based voting system & $\begin{array}{c}\text { Generation-based voting } \\
\text { system }\end{array}$ \\
\hline Temporary & Current voting system & Age-based voting system \\
\hline & $\begin{array}{l}\text { Demeny voting system } \\
\text { Demeny (1986) }\end{array}$ & Ihori and Doi (1998) \\
\hline Lifespan & $\begin{array}{l}\text { Voting system that allocates } \\
\text { parliamentary seats according to life } \\
\text { expectancy and region (hereafter life } \\
\text { expectancy and region-based) }\end{array}$ & $\begin{array}{l}\text { Voting system that allocates } \\
\text { parliamentary seats according to life } \\
\text { expectancy and age (hereafter life } \\
\text { expectancy and age-based) } \\
\text { Takeuchi (2011) }\end{array}$ \\
\hline
\end{tabular}

Source: Authors of this paper

As shown in Table 1, by classifying calculated vote equality into temporary and lifespan and vote-value equality as region-based or generation-based, the current and Demeny voting systems are considered to be temporary and region-based, whereas Ihori and Doi's (1998) proposed system is considered to be temporary and generation-based. The voting system proposed by Takeuchi (2011) is considered to be lifespan and generation-based, while the life expectancy-based voting system that sets constituency bloc allocations by region is considered to be lifespan and region-based. 


\section{The Model}

\section{(1) Household Sector}

We assume there are two generations for each period $t(\mathrm{t}=1,2,3$, etc.); generation $t$ is in the working period and generation $t-1$ is in the retired period. Based on an inelastic supply of labor, we assume each generation $t$ earns a wage income $e_{t}$ in the working period (period $t$ ) and receives a public pension $b_{t+1}$ in the retired period (period $t+1$ ). Lifetime consumption per capita, which generation $t$ forecasts in the working period (period $t$ ), is denoted by $C_{t}$. Then, the lifetime budget constraint of generation $t$ is described as follows, where $1 / \beta$ specifies the exogenous gross interest rate and $\tau$ the wage tax rate:

$$
C_{t}=e_{t}(1-\tau)+\beta b_{t+1}
$$

For analytical simplicity, this model assumes that the lifetime utility function is defined as a linear function of corresponding lifetime consumption. In addition, each generation is assumed to behave in a self-serving manner. Therefore, each generation $t$ will maximize the following lifetime utility during period $t$ (i.e., the working period):

$$
U_{t}=C_{t}
$$

In the same manner, each generation $t-1$ will maximize the public pension $b_{t}$ receivable during period t (i.e., the retired period). ${ }^{7}$

\section{(2) Government Sector}

For each period $t$, the government collects wage taxes from the working generation (generation $t$ ) to finance public investment (e.g., science and technology R\&D) for future growth $R_{t}$ and to allocate

\footnotetext{
${ }^{7}$ Let $S_{t}$ indicate the amount saved by generation $t-1$ during their working lives (period $t-1$ ). In this case, rigorously speaking, generation $t$-1 maximizes the sum of savings $\beta s_{t}$ accumulated in period $t$ and pension income $b_{t}$ received during the retired period. However, since savings $\beta s_{t}$ is an exogenous variable in period $t$, public pension income $b_{t}$ can be considered the maximand here.
} 
public pension payments $B_{t}$. Let $\lambda_{t}$ be the rate of public investment as part of the entire government budget, $N_{t}$ the population of generation $t$, and $n$ the gross growth rate for the generational population. Then, $B_{t}=b_{t} N_{t-1}$ and $N_{t}=n N_{t-1}$ hold, and the following represent the budget constraint for public investment and the public pension plan, respectively:

$$
\begin{aligned}
& R_{t}=\lambda_{t} e_{t} \tau N_{t} \\
& B_{t}=\left(1-\lambda_{t}\right) e_{t} \tau N_{t}
\end{aligned}
$$

\section{(3) Production Sector}

A representative firm has the following production function in this model ${ }^{8}$

$$
Y_{t}=e_{t} L_{t}
$$

Here, $e_{t}$ represents technology stock. The next period's technology stock $e_{t+1}$, as explained from the perspective of the endogenous growth theory presented by Romer (1986), is the function of the current period's public investment (relative to GDP) $R_{t} / Y_{t}$ and the current period's technology stock $e_{t}$. Note that $\gamma$ and $\alpha$ are exogenous variables that express the degree to which public investment contributes to the increase in technology stock:

$$
\frac{e_{t+1}-e_{t}}{e_{t}}=\gamma\left(\frac{R_{t}}{Y_{t}}\right)^{\alpha} \quad \gamma>0 \text { and } \alpha>0
$$

\section{(4) Political Objective Function}

For every period $t$, we assume that $\lambda_{t}$, the rate of public investment as a proportion of the entire government budget, is determined in order to maximize the following objective function: the weighted average of the working generation lifetime utility $U_{t}$ and retired generation utility $b_{t}$, based on political intervention and the interaction between the working generation (generation $t$ ) and

\footnotetext{
${ }^{8}$ The model used for this study omits the accumulation of physical capital for simplicity.
} 
retired generation (generation $t-1):^{9}$

$$
W_{t}=\theta_{t} N_{t} C_{t}+\theta_{t-1} N_{t-1} b_{t}
$$

Here, $\theta_{t}$ and $\theta_{t-1}$ are exogenous parameters that represent the political power between the working generation (generation $t$ ) and retired generation (generation $t-1)$.

In this case, the current voting system is normalized to $\theta_{t}=1$ and $\theta_{t-1}=\rho>1$ (as shown in Figure 2). There are two reasons for assuming $\rho>1$. The first reason is vote-value disparity, which is caused by the discrepancy between urban areas dominated by younger voters and regional areas dominated by older voters. Therefore, the retired generation has more political strength than the working generation. ${ }^{10}$ The second reason is age-based turnout disparity. As Figure 3 illustrates, voter turnout for the retired generation is higher than that for the working generation (voters in their 20 s to 50 s). As such, $\rho$ represents vote-value disparity and age-based turnout disparity.

Under the life expectancy and region-based voting system, the parameters would be $\theta_{t}=k>1$ and $\theta_{t-1}=\rho>1$ (as shown in Table 2). For example, if the lifetime of each voter is 100 years, the working generation represents individuals in their 20 s to 50 s and the retired generation includes those in their $60 \mathrm{~s}$ to $90 \mathrm{~s}$; thus, $k=3$. Since the average age in the working generation is 40 years $(20+59) / 2)$ and that in the retired generation is 80 years $(60+99) / 2)$, the life expectancy of the former can be construed as 60 years and that of the latter as 20 years. Accordingly, as the ratio of the voting volume between the working and retired generations is $3: 1$, the working generation seems to have three times as much voting power as the retired generation. However, as the voting system is region-based, the regional retired generation has more political power than the urban

\footnotetext{
9 Such a formulation appears in D'Amato and Galasso (2010).

${ }^{10}$ On March 23, 2012, the Japanese Supreme Court made an extremely important decision concerning the issue of vote-value disparity. It ruled that the proportional representation system used in the August 2009 Lower House elections, which showed a vote-value disparity of up to 2.3-fold, was unconstitutional. By allocating extra seats to sparsely populated regions, this system violates the Constitution, which ensures an equal representation of votes. In the past, the Supreme Court ruled a vote-value disparity of threefold or less to be constitutional, but it has since agreed with those that seek to abolish the method.
} 
retired generation. Therefore, in the life expectancy and region-based voting system with $k=3$, $\theta_{t}=3$ and $\theta_{t-1}=\rho>1$ hold.

However, in the life expectancy and age-based voting system, the parameters would be $\theta_{t}=k>1$ and $\theta_{t-1}=1$ (see Table 2). This indicates that $\rho=1$, since the voting system is generation-based, and in the above case with $k=3$, the number of Diet seats allocated to the working and retired generations has a 3:1 ratio. As Diet seat allocation should in no way be influenced by (interregional) vote-value disparity or age-based voter turnout disparity, the working generation has three times the political strength of the retired generation. Therefore, for the life expectancy and age-based voting system with $k=3, \theta_{t}=3$ and $\theta_{t-1}=1$ hold.

Table 2. Political Strength of the Working and Retired Generations

\begin{tabular}{l|c|c|c}
\hline & & $\theta_{t}$ & $\theta_{t-1}$ \\
\hline Voting System 1 & Current voting system & 1 & $\rho>1$ \\
\hline Voting System 2 & $\begin{array}{c}\text { Life expectancy and region-based } \\
\text { voting system }\end{array}$ & $k>1$ & $\rho>1$ \\
\hline Voting System 3 & Life expectancy and age-based \\
& voting system & $k>1$ & 1 \\
\hline
\end{tabular}

Table 3. Age-based Voter Turnout Transition

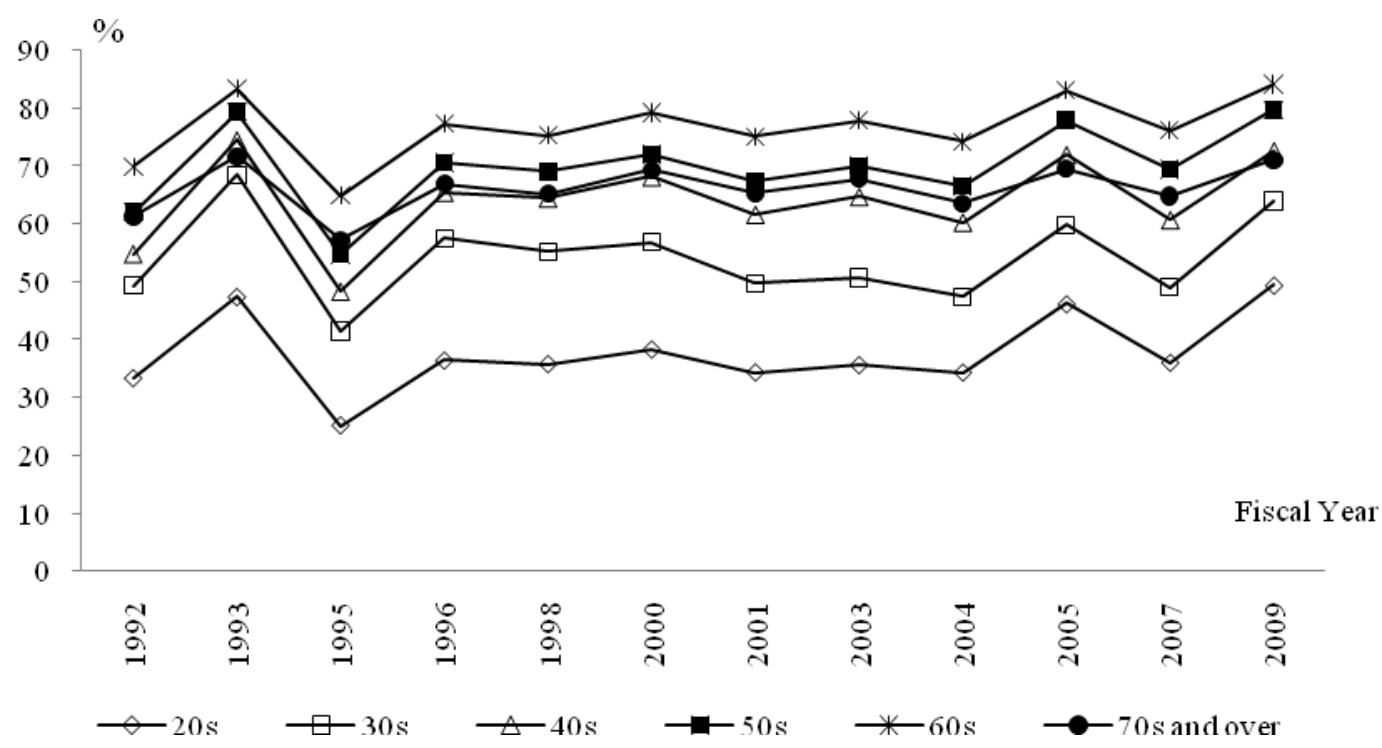

Source: Compiled from data on the Association for Promoting Fair Elections website 


\section{Analysis}

\section{(1) Political Equilibrium}

From equations (3) and (5), assuming labor supply $N_{t}$ and labor demand $L_{t}$ correspond, and assuming that a labor market equilibrium is achieved, equation (6) can be represented as follows:

$$
e_{t+1}=\left(1+\gamma\left(\tau \lambda_{t}\right)^{\alpha}\right) e_{t} \equiv m\left(\lambda_{t}\right) e_{t}
$$

By substituting equation (8) into equation (4), the following is obtained:

$$
b_{t+1}=\left(1-\lambda_{t+1}\right) \operatorname{tnm}\left(\lambda_{t}\right) e_{t}
$$

In this case, the optimization problem of equation (7) is expressed as follows. Note that $\sigma_{t}=\theta_{t-1} / n \beta \theta_{t}$

$$
\begin{aligned}
\lambda\left(\sigma_{t}\right) & =\underset{\lambda_{t}}{\arg \max }\left(\theta_{t} N_{t} C_{t}+\theta_{t-1} N_{t-1} b_{t}\right) \\
& =\underset{\lambda_{t}}{\arg \max }\left(b_{t+1}+\sigma_{t} b_{t}\right)=\underset{\lambda_{t}}{\arg \max }\left(\left(1-\lambda_{t+1}\right) \operatorname{tnm}\left(\lambda_{t}\right) e_{t}+\sigma_{t}\left(1-\lambda_{t}\right) \tau n e_{t}\right) \\
& =\underset{\lambda_{t}}{\arg \max }(\underbrace{\left(1-\lambda_{t+1}\right) m\left(\lambda_{t}\right)}+\underbrace{\sigma_{t}\left(1-\lambda_{t}\right)})
\end{aligned}
$$

Working generation benefits Retired generation benefits

The parentheses on the right-hand side of equation (10) represent the functions of the endogenous variables $\lambda_{t}$ and $\lambda_{t+1}$. Here, $\lambda_{t}$ is determined in period $t$, whereas $\lambda_{t+1}$ is determined in period $t+1$. When optimizing equation (10), $\lambda_{t}$ cannot be determined if $\lambda_{t+1}$ is not predetermined. The following assumption is set as a "political commitment" for $\lambda_{t+1}$ in order to resolve this problem. This is equivalent to the assumption that the working and retired generations, both believing 
$E_{t}\left(\lambda_{t+1}\right)=\lambda_{t}$, behave in a self-serving manner when voting. ${ }^{11}$

\section{Assumption 1: Political commitment}

The political commitment for each period $t$ is $\lambda_{t+1}=\lambda_{t}$.

Let us find the optimum solution for equation (10) under Assumption 1. Although $\alpha$ could be given various values, let us assume $\alpha=1$ for simplicity. In this case, the optimum solution for equation (10) would be derived as follows:

$$
\lambda\left(\sigma_{t}\right)=\max \left\{\frac{\gamma \tau-\left(1+\sigma_{t}\right)}{2 \gamma \tau}, 0\right\}
$$

Equation (11) is the function of relative political strength $\sigma_{t}$, which reflects the relationship between the political strength $\left(\theta_{t}, \theta_{t-1}\right)$ of the working and retired generations. However, if we continue to adopt the same voting system (e.g., the life expectancy and region voting system), $\theta_{t}$ and $\theta_{t-1}$ in Table 2 can be assumed to be stable for each period. Further, if the gross growth rate of the generational population $(n)$ is constant, there is a high probability that relative political strength $\left(\sigma_{t}\right)$ will also be stable. With this as the background, let us add one more assumption.

\section{Assumption 2: Relative political strength of a voting system}

Under the same voting system, relative political strength $\left(\sigma_{t}\right)$ remains constant $(\sigma)$.

In this situation, equation (11) and Assumption 2 suggest the following proposition.

\section{Proposition 1: Public investment rate}

11 Optimizing equation (10) with respect to $\lambda_{t}$, when $\lambda_{t+1}$ is a given variable, yields $\lambda_{t}=\Gamma\left(\lambda_{t+1}, \sigma_{t}\right)=\left(\alpha \gamma \tau^{\alpha}\left(1-\lambda_{t+1}\right) / \sigma_{t}\right)^{t /(1-\alpha)}$. Then, assuming the steady state of $(\lambda=\Gamma(\lambda, \sigma))$, the public investment rate can be derived with $\lambda_{t}=\Gamma\left(\Gamma\left(\ldots \Gamma(\lambda, \sigma) \ldots, \sigma_{t+1}\right), \sigma_{t}\right)$ as the forward-looking solution. 
If the voting system (relative political strength $\sigma$ ) represented by equations (1) to (7) is invariant, the optimized public investment rate $\left\{\lambda_{t}=\lambda(\sigma)\right\}_{t=0}^{\infty}$ can be derived uniquely from the political objective function in equation (10).

\section{Corollary 1:}

(i) When the degree to which public investment contributes to the increase in technical stock $\gamma$ satisfies $\gamma \leq(1+\sigma) / \tau$, the set of the optimized public investment rate is derived as $\left\{\lambda_{t}=0\right\}_{t=0}^{\infty}$.

(ii) When $\gamma>(1+\sigma) / \tau$ is satisfied, the set of optimized public investment, solved uniquely, is always positive $\left\{\lambda_{t}>0\right\}_{t=0}^{\infty}$.

Further, since Proposition 1 provides a public investment rate $\left\{\lambda_{t}=\lambda(\sigma)\right\}_{t=0}^{\infty}$, if technical stock initial value $e_{0}$ is given, $\left\{C_{t}(\sigma), b_{t}(\sigma)\right\}_{t=0}^{\infty}$, the predicted lifetime consumption of the working generation and public pension received by the retired generation for period $t$, can be derived uniquely. In light of the foregoing, we define the following.

\section{Definition 1: Political equilibrium}

Political equilibrium $V(\sigma)$ is defined as the set $\left\{C_{t}(\sigma), b_{t}(\sigma)\right\}_{t=0}^{\infty}$ derived under a constant voting system (relative political strength $\sigma$ ) and initial technical stock value $e_{0}$.

\section{(2) Benefits for the working and retired generations}

Note that the first term within the parentheses on the right-hand side of equation (10) corresponds to the predicted lifetime utility $\left(U_{t}\right)$ for period $t$ of the working generation, while the second term is the utility $\left(b_{t}\right)$ gained from the public pension received by the retired generation in period $t$. The 
relationship between each utility and the public investment rate is, when $\alpha=1$ is taken, described in Figure 1.

\section{Figure 1.}

Working generation utility $\left(U_{t}\right)$

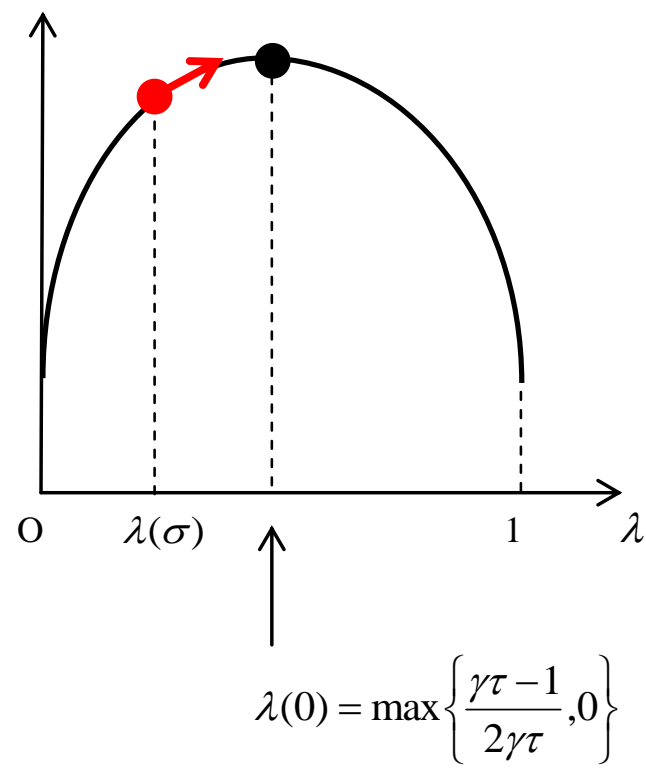

Retired generation utility $\left(b_{t}\right)$

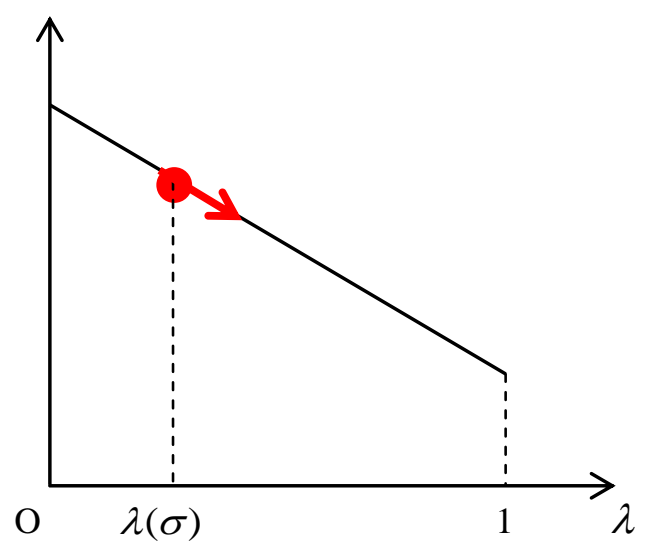

As described in Table 2, each relative political strength and public investment rate in equation (11) satisfies the following relationship, where the current voting system is termed $v 1$, the life expectancy and region-based voting system $v 2$, and the life expectancy and age-based voting system $\nu 3$. Hereafter, the case (ii) of corollary 1 is assumed $(\gamma \tau>1+\rho / n \beta)$ :

$$
\begin{aligned}
& \sigma^{\nu 1}=\rho / n \beta>\sigma^{\nu 2}=\rho / k n \beta>\sigma^{\nu 3}=1 / k n \beta \\
& \lambda\left(\sigma^{\nu 1}\right)<\lambda\left(\sigma^{\nu 2}\right)<\lambda\left(\sigma^{\nu 3}\right)<\lambda(0)
\end{aligned}
$$

From equation (12) and Table 2, the following sequences hold: working generation utility $U_{t}\left(\sigma^{\nu 1}\right)<U_{t}\left(\sigma^{\nu 2}\right)<U_{t}\left(\sigma^{\nu 3}\right)$ and retired generation utility $b_{t}\left(\sigma^{\nu 1}\right)>b_{t}\left(\sigma^{\nu 2}\right)>b_{t}\left(\sigma^{\nu 3}\right)$. When transition occurs from the current voting system to a life expectancy-based voting system (voting systems 2 and 3), the temporal perspective for policymaking lengthens; moreover, the public investment rate increases, indicating an improvement in the predicted lifetime utility $\left(U_{t}\right)$ for the 
working generation. However, the retired generation may reject the transition to this voting system, as it would result in reduced retired generation utility $\left(b_{t}\right)$. Therefore, the possibility of moving from the current voting system to a life expectancy-based voting system (voting systems 2 and 3 ) is unclear.

\section{(3) The possibility of moving to a life expectancy-based voting system}

Nevertheless, the working generation does benefit from a change to the voting system. Therefore, we can envision the case where the two generations enter into an "intergenerational contract" in which the working generation makes a lump-sum transfer $\left(T=n \varphi e_{t}>0\right)$ to the retired generation in order to compensate for their losses. This transfer may facilitate the transition from the current voting system to a life expectancy-based voting system (voting systems 2 and 3). Thus, we establish the following definitions.

\section{Definition 2: The possibility of moving to political equilibrium}

In this definition, we set the present time to period $t$ and consider two political equilibria $V(\sigma)$ and $V\left(\sigma^{\prime}\right)$. If there exists a positive value $\varphi$ that satisfies the following inequalities with the utilities of the working and retired generations, the transition from political equilibrium $V(\sigma)$ to political equilibrium $V\left(\sigma^{\prime}\right)$ would be possible:

$$
C_{t}\left(\sigma^{\prime}\right)-\varphi e_{t} \geq C_{t}(\sigma) \text { and } b_{t}\left(\sigma^{\prime}\right)+n \varphi e_{t} \geq b_{t}(\sigma)
$$

The above inequalities show that the condition maintains or increases the utilities of both the retired generation and the working generation. From this finding, we arrive at the following proposition.

\section{Proposition 2: The possibility of moving to a life expectancy-based voting system}

(i) Consider two voting systems $\sigma$ and $\sigma^{\prime}$ with $\sigma \equiv \theta_{t-1} / n \beta \theta_{t}$ and $\sigma^{\prime} \equiv \theta_{t-1}{ }^{\prime} / n \beta \theta_{t}{ }^{\prime}$. Here, 
we consider the case $\sigma>\sigma^{\prime}$. Then, the transition from voting system $\sigma$ to voting system $\sigma^{\prime}$ is possible if and only if $\theta_{t-1} / \theta_{t}+\theta_{t-1}{ }^{\prime} / \theta_{t}^{\prime} \geq 2$ is satisfied or, equivalently, $\sigma+\sigma^{\prime} \geq 2 / n \beta$ is satisfied.

(ii) Consider three voting systems $\sigma, \sigma^{\prime}$, and $\sigma^{\prime \prime}$ with $\sigma \equiv \theta_{t-1} / n \beta \theta_{t}, \sigma^{\prime} \equiv \theta_{t-1}{ }^{\prime} / n \beta \theta_{t}{ }^{\prime}$, and $\sigma^{\prime \prime} \equiv \theta_{t-1}{ }^{\prime \prime} / n \beta \theta_{t}{ }^{\prime \prime}$. Here, we consider the case $\sigma>\sigma^{\prime}>\sigma^{\prime \prime}$. If the transition from political equilibrium $V(\sigma)$ to political equilibrium $V\left(\sigma^{\prime \prime}\right)$ is possible, the transition from political equilibrium $V(\sigma)$ to political equilibrium $V\left(\sigma^{\prime}\right)$ is also possible.

(iii) When $\rho \geq \rho_{1} \equiv 2 k /(k+1)$ is satisfied, the transition from the current voting system to a life expectancy and region-based voting system is possible.

(iv) When $\rho \geq \rho_{2} \equiv(2 k-1) / k$ is satisfied, the transition from the current voting system to a life expectancy and age-based voting system is possible.

Proof: Refer to Appendix 1. .

Now that we assume $k>1, \rho_{2}>\rho_{1}$ always holds for both (iii) and (iv) in Proposition 2, which is a direct consequence of (ii). In addition, when transitions to voting systems 2 and 3 are both possible, equation (12) and Appendices (A5) and (A6) show a higher increase in working generation utility $\left(U_{t}\right)$ for voting system 3. Equation (12) also indicates the utility of future generations for generation $t$ and beyond is higher in voting system 3 than it is in voting system 2 . Thus, the following corollary holds.

\section{Corollary 2:}

When $\rho \geq(2 k-1) / k$ is satisfied, the utility of the working generation and future generations increases more by moving from the current voting system to the life expectancy and age-based voting system rather than by moving to the life expectancy and region-based voting system.

Although the analyses thus far (equation (11) and later) deal with the case when $\alpha=1$, the 
following proposition holds when $\alpha=0.5$.

Proposition 3: The possibility of moving to a life expectancy-based voting system when $\alpha=0.5^{12}$

Consider two voting systems $\sigma$ and $\sigma^{\prime}$ with $\sigma \equiv \theta_{t-1} / n \beta \theta_{t}$ and $\sigma^{\prime} \equiv \theta_{t-1}{ }^{\prime} / n \beta \theta_{t}^{\prime}$. Here, we consider the case $\sigma>\sigma^{\prime}$. Then, assuming the public commitment is $\lambda_{t+1}=\lambda_{t}$, moving from voting system $\sigma$ to voting system $\sigma^{\prime}$ is possible if and only if the following conditions are satisfied:

(i) If positive value $\gamma$ is sufficiently small: $1 /(1+\sigma)+1 /\left(1+\sigma^{\prime}\right) \leq 2 n \beta /(1+n \beta)$

(ii) If positive value $\gamma$ is sufficiently large: $\sigma+\sigma^{\prime} \geq 2 / n \beta$

\section{Proof: Refer to Appendix 2.}

Note that either case in Proposition 3 implies that the necessary and sufficient condition for the transition possibility is satisfied if $\sigma$ and $\sigma^{\prime}$, the latter of which must be less than the former, are both sufficiently large. Thus, considering three voting systems $\sigma, \sigma^{\prime}$, and $\sigma^{\prime \prime}$ with $\sigma>\sigma^{\prime}>\sigma^{\prime \prime}$, if the transition from political equilibrium $V(\sigma)$ to political equilibrium $V\left(\sigma^{\prime \prime}\right)$ is possible, the transition from political equilibrium $V(\sigma)$ to political equilibrium $V\left(\sigma^{\prime}\right)$ is also possible.

We chose the cases of $\alpha=1$ and $\alpha=0.5$ for analytical simplicity. However, although it is impossible to solve the equations explicitly in a general case, some of the above-mentioned characteristics are universally valid for any $\alpha$ not greater than 1 . We finally derive such universal characteristics under the assumption of political commitment.

12 Appendix 3 presents the results when $\lambda$ is determined as the forward-looking solution with $\alpha=0.5$ and $\sigma>\sigma^{\prime}$ satisfied, as in Proposal 3 . 


\section{Proposition 4: The possibility of moving to a life expectancy-based voting system in any $\alpha$}

not greater than 1

(i) Consider two voting systems $\sigma$ and $\sigma^{\prime}$ with $\sigma \equiv \theta_{t-1} / n \beta \theta_{t}$ and $\sigma^{\prime} \equiv \theta_{t-1}{ }^{\prime} / n \beta \theta_{t}{ }^{\prime}$. Here, we consider the case $\sigma>\sigma^{\prime}$. Then, the transition from voting system $\sigma$ to voting system $\sigma^{\prime}$ is possible if and only if both $\sigma$ and $\sigma^{\prime}$ are sufficiently large.

(ii) Consider three voting systems $\sigma, \sigma^{\prime}$, and $\sigma^{\prime \prime}$ with $\sigma \equiv \theta_{t-1} / n \beta \theta_{t}, \sigma^{\prime} \equiv \theta_{t-1}{ }^{\prime} / n \beta \theta_{t}{ }^{\prime}$, and $\sigma^{\prime \prime} \equiv \theta_{t-1}{ }^{\prime \prime} / n \beta \theta_{t}{ }^{\prime \prime}$. Here, we consider the case $\sigma>\sigma^{\prime}>\sigma^{\prime \prime}$. If the transition from political equilibrium $V(\sigma)$ to political equilibrium $V\left(\sigma^{\prime \prime}\right)$ is possible, the transition from political equilibrium $V(\sigma)$ to political equilibrium $V\left(\sigma^{\prime}\right)$ is also possible.

Proof: Result (ii) is a direct consequence of result (i). For result (i), refer to Appendix 4 .

\section{Concluding remarks}

This paper constructed an OLG model in order to demonstrate how political intervention and interaction in the working and retired generations affect the allocation rate in future growth-stimulating public investment and the public pension. It also analyzed the possibility of moving to a voting system where parliamentary seats are allocated according to life expectancy.

The results presented herein led us to draw three main conclusions. Firstly, we noted the importance of the voting system when population demographics change. In countries such as Japan that are experiencing declining birthrates and an aging population, when eligible voters are self-serving and behave according to the lifecycle hypothesis, this behavior is likely to shorten the temporal perspective for policymaking over time. Any theoretical transition from the current voting system to a life expectancy-based voting system would thus lengthen the temporal perspective for policymaking, potentially increasing the public investment rate and improving the utilities of the working and future generations. 
Secondly, when age-based voting turnout disparity is higher than a specified value, the shift from the current voting system to a life expectancy and region-based voting system or a life expectancy and age-based voting system is possible. Thirdly, if both transitions are possible, moving to the latter would offer greater potential for increasing the utilities of the working and future generations than moving to the former.

We propose the following topics for future discussion. Firstly, the theoretical model used in this study could be improved, as it assumes the presence of only two generations for each period and that the production function consists of only two factors (i.e., technical stock and labor) with no influence from capital. With such an elastic assumption, considering how to modify the proposals introduced herein is of utmost importance and requires further discussion.

The second issue is determining the conditions of the exogenous variables $\alpha, \gamma$, and $\rho$. The variables $\alpha$ and $\gamma$ concern the degree to which public investment contributes to an increase in technical stock, while $\rho$ is related to vote-value disparity and age-based voting turnout disparity. The analysis conducted in this study assumed $\alpha=1$ and $\gamma \tau>1+\rho / n \beta$. However, in a true economic situation, these conditions may not be satisfied, and the model may therefore require modification. This point also requires further clarification in future research.

The third topic is the relationship between demographic changes and policymaking. Our study assumed that each generation is selfish and behaves according to the lifecycle hypothesis, while the declining birthrate and aging population was shown to be a mechanism for shortening the temporal perspective of policymaking. As such mechanisms grow stronger in reality, investigating systems that correct for such influences (e.g., public budget management rules and the application of intergenerational accounting) will become mandatory. Such analysis will be highly significant not only for voting systems, but also for other issues and it should receive further discussion in the future. 


\section{Appendix 1}

Let us examine the possibility of moving from voting system $\sigma$ to voting system $\sigma^{\prime}$ based on the two voting systems that satisfy $\sigma>\sigma^{\prime}: \sigma \equiv \theta_{t-1} / n \beta \theta_{t}$ and $\sigma^{\prime} \equiv \theta_{t-1}{ }^{\prime} / n \beta \theta_{t}{ }^{\prime}$. First, the conditions for equation (13) are equivalent to the following:

$$
\begin{aligned}
& \left\{\begin{array}{l}
\beta \tau n e_{t}\left\{\left(1-\lambda^{\prime}\right) m\left(\lambda^{\prime}\right)-(1-\lambda) m(\lambda)\right\} \geq \varphi e_{t} \\
\left(1-\lambda^{\prime}\right) \tau n e_{t}-(1-\lambda) \tau n e_{t} \geq-n \varphi e_{t}
\end{array}\right. \\
& \Leftrightarrow \\
& \left\{\begin{array}{l}
\beta \tau n\left\{\left(1-\lambda^{\prime}\right) m\left(\lambda^{\prime}\right)-(1-\lambda) m(\lambda)\right\} \geq \varphi \\
\left(\lambda^{\prime}-\lambda\right) \tau \leq \varphi
\end{array}\right.
\end{aligned}
$$

Here, equation (A4) is equivalent to:

$$
\left(\frac{\gamma \tau-\left(1+\sigma^{\prime}\right)}{2 \gamma \tau}-\frac{\gamma \tau-(1+\sigma)}{2 \gamma \tau}\right) \tau \leq \varphi \Leftrightarrow \frac{\sigma-\sigma^{\prime}}{2 n} \leq \varphi
$$

and equation (A3) is equivalent to:

$$
\begin{aligned}
& \frac{\beta \tau n}{\gamma \tau}\left[\begin{array}{l}
\left(\frac{1+\gamma \tau}{2}+\frac{\sigma^{\prime}}{2}\right)\left(\frac{1+\gamma \tau}{2}-\frac{\sigma^{\prime}}{2}\right) \\
-\left(\frac{1+\gamma \tau}{2}+\frac{\sigma^{\prime}}{2}\right)\left(\frac{1+\gamma \tau}{2}-\frac{\sigma}{2}\right)
\end{array}\right] \geq \varphi \\
& \Leftrightarrow \\
& \frac{n \beta\left(\sigma-\sigma^{\prime}\right)\left(\sigma+\sigma^{\prime}\right)}{4 \gamma} \geq \varphi
\end{aligned}
$$

From (A5) and (A6) above, we ascertain that the conditions for the possibility of transition described in equation (13) are equivalent to having $\varphi$ that satisfies the following: 


$$
\frac{\sigma-\sigma^{\prime}}{2 \gamma} \leq \varphi \leq \frac{n \beta\left(\sigma-\sigma^{\prime}\right)\left(\sigma+\sigma^{\prime}\right)}{4 \gamma}
$$

In the present study of the possibility of moving to a voter system that satisfies $\sigma>\sigma^{\prime}$, we found that the abovementioned $\varphi$ exists if and only if the following condition holds:

$$
\frac{2}{n \beta} \leq \sigma+\sigma^{\prime} \Leftrightarrow 2 \leq \frac{\theta_{t-1}}{\theta_{t}}+\frac{\theta_{t-1}^{\prime}}{\theta_{t}^{\prime}}
$$

If $\sigma>\sigma^{\prime}>\sigma^{\prime \prime}$, it is clear that $\frac{2}{n \beta} \leq \sigma+\sigma^{\prime \prime}$ implies $\frac{2}{n \beta} \leq \sigma+\sigma^{\prime}$.

Note that in the current voting system, $\theta_{t-1} / \theta_{t}=\rho$; in voting system $2, \theta_{t-1}{ }^{\prime} / \theta_{t}{ }^{\prime}=\rho / k$; and in voting system $3, \theta_{t-1}{ }^{\prime} / \theta_{t}{ }^{\prime}=1 / k$. Therefore, the following are the necessary and sufficient conditions to establish the possibility of moving from the current voting system to either voting system 2 or voting system 3 :

The necessary and sufficient condition for moving to system 2: $\rho \geq 2 k /(k+1)$

The necessary and sufficient condition for moving to system 3: $\rho \geq(2 k-1) / k$ 


\section{Appendix 2}

Under Assumption 1 (political commitment), let us consider the case with $\alpha=0.5$. Then, the optimization problem is represented as follows:

$$
\lambda(\sigma)=\underset{\lambda}{\arg \max }[(1-\lambda)(1+\sigma+\gamma \sqrt{\tau \lambda})]
$$

By solving this problem, we obtain the following:

$$
\lambda=\frac{2(1+\sigma)^{2}-2(1+\sigma) \sqrt{(1+\sigma)^{2}+3 \gamma^{2} \tau}+3 \gamma^{2} \tau}{9 \gamma^{2} \tau}
$$

From Appendices (A-3), (A-4), and (B-2), as well as $m(\lambda)=1+\gamma \sqrt{\tau \lambda}$, the transition is possible if and only if the following holds:

$$
\left\{\begin{array}{l}
\beta \tau n\left\{\begin{array}{l}
-\left(\frac{2\left(1+\sigma^{\prime}\right)^{2}-6 \gamma^{2} \tau-2\left(1+\sigma^{\prime}\right) \sqrt{\left(1+\sigma^{\prime}\right)^{2}+3 \gamma^{2} \tau}}{9 \gamma^{2} \tau}\right)\left(\frac{2-\sigma^{\prime}+\sqrt{\left(1+\sigma^{\prime}\right)^{2}+3 \gamma^{2} \tau}}{3}\right) \\
+\left(\frac{\left.2(1+\sigma)^{2}-6 \gamma^{2} \tau-2(1+\sigma) \sqrt{(1+\sigma)^{2}+3 \gamma^{2} \tau}\right)\left(\frac{2-\sigma+\sqrt{(1+\sigma)^{2}+3 \gamma^{2} \tau}}{3}\right)}{9 \gamma^{2} \tau}\right)
\end{array}\right\} \geq \varphi \\
\frac{1}{9 \gamma^{2}}\left[\begin{array}{l}
\left(2\left(1+\sigma^{\prime}\right)^{2}-2\left(1+\sigma^{\prime}\right) \sqrt{\left(1+\sigma^{\prime}\right)^{2}+3 \gamma^{2} \tau}\right) \\
-\left(2(1+\sigma)^{2}-2(1+\sigma) \sqrt{(1+\sigma)^{2}+3 \gamma^{2} \tau}\right)
\end{array} \leq \varphi\right.
\end{array}\right.
$$

Appendices (B-3) and (B-4) explain that $\varphi$, which assures the transition, exists if and only if the following holds:

$$
\begin{aligned}
& \left(2\left(1+\sigma^{\prime}\right)^{2}-2\left(1+\sigma^{\prime}\right) \sqrt{\left(1+\sigma^{\prime}\right)^{2}+3 \gamma^{2} \tau}\right) \\
& +\frac{\beta n}{3}\left(2\left(1+\sigma^{\prime}\right)^{2}-6 \gamma^{2} \tau-2\left(1+\sigma^{\prime}\right) \sqrt{\left(1+\sigma^{\prime}\right)^{2}+3 \gamma^{2} \tau}\right)\left(2-\sigma^{\prime}+\sqrt{\left(1+\sigma^{\prime}\right)^{2}+3 \gamma^{2} \tau}\right) \\
& \leq\left(2(1+\sigma)^{2}-2(1+\sigma) \sqrt{(1+\sigma)^{2}+3 \gamma^{2} \tau}\right) \\
& +\frac{\beta n}{3}\left(2(1+\sigma)^{2}-6 \gamma^{2} \tau-2(1+\sigma) \sqrt{(1+\sigma)^{2}+3 \gamma^{2} \tau}\right)\left(2-\sigma+\sqrt{(1+\sigma)^{2}+3 \gamma^{2} \tau}\right)
\end{aligned}
$$


We then approximate (B-5) into two categories: when positive value $\gamma$ is sufficiently small or large.

(i) Firstly, when positive value $\gamma$ is sufficiently small, taking Taylor's series of (B-5) and approximating by taking only the fourth Taylor polynomial or below, (B-5) takes the form

$\frac{1}{\left(1+\sigma^{\prime}\right)^{2}}+\frac{1}{\left(1+\sigma^{\prime}\right)^{2}} \beta n-\frac{2}{\left(1+\sigma^{\prime}\right)} \beta n \leq \frac{1}{(1+\sigma)^{2}}+\frac{1}{(1+\sigma)^{2}} \beta n-\frac{2}{(1+\sigma)} \beta n$

The above form is equivalent to

$\frac{1}{1+\sigma^{\prime}}+\frac{1}{1+\sigma} \leq \frac{2 \beta n}{1+\beta n}$

which can be modified to

$\frac{\varepsilon^{\prime}}{1+\varepsilon^{\prime}}+\frac{\varepsilon}{1+\varepsilon} \geq 0$

by substituting $\sigma=\frac{1}{\beta n}+\left(1+\frac{1}{\beta n}\right) \varepsilon$ and $\sigma^{\prime}=\frac{1}{\beta n}+\left(1+\frac{1}{\beta n}\right) \varepsilon^{\prime}$.

Here, we stress that the above condition is similar to the necessary and sufficient condition derived in Proposition 2 (i) $\frac{2}{\beta n} \leq \sigma+\sigma^{\prime} \Leftrightarrow \varepsilon+\varepsilon^{\prime} \geq 0$, which assures the transition when $\alpha=1$.

(ii) Secondly, when positive value $\gamma$ is sufficiently large, (B-5) becomes

$$
\frac{2}{\beta n} \leq \sigma+\sigma^{\prime}
$$

which is equivalent to the necessary and sufficient condition derived in Proposition 2 (i), which assures the transition when $\alpha=1$. 


\section{Appendix 3}

In a forward-looking equation, when $\alpha=0.5$, the optimization problem related to equation (10) can be expressed as follows:

$\lambda\left(\sigma_{t}\right)=\left.\underset{\lambda_{t}}{\arg \max }\left(\left(1-\lambda_{t+1}\right)\left(1+\gamma \tau^{\frac{1}{2}} \lambda_{t}^{\frac{1}{2}}\right)+\sigma_{t}\left(1-\lambda_{t}\right)\right)\right|_{\lambda_{t+1} \text { fixed }}$

Accordingly, in a forward-looking solution,

$\lambda_{t}=\frac{\gamma^{2} \tau\left(1-\lambda_{t+1}\right)^{2}}{4 \sigma_{t}^{2}}$

where the steady state is expressed as follows:

$\lambda=\frac{\gamma^{2} \tau(1-\lambda)^{2}}{4 \sigma_{t}^{2}}$

Hence, the forward-looking solution can be expressed as:

$\lambda^{*}=1+2 \sigma_{t} \frac{\sigma_{t}-\sqrt{\gamma^{2} \tau+\sigma_{t}^{2}}}{\gamma^{2} \tau}$

We assume that the forward-looking solution $\lambda^{*}(\sigma)$ is determined under the projection that relative political strength $(\sigma)$ is hypothetically perpetual.

Next, let us examine the possibility of moving from $\sigma$ to $\sigma^{\prime}$, assuming $\sigma>\sigma^{\prime}$ without any loss of generality. In Appendices (A-3), (A-4), and (C-4), as well as $m(\lambda)=1+\gamma \sqrt{\tau \lambda}$, the transition is possible if and only if the following inequalities hold:

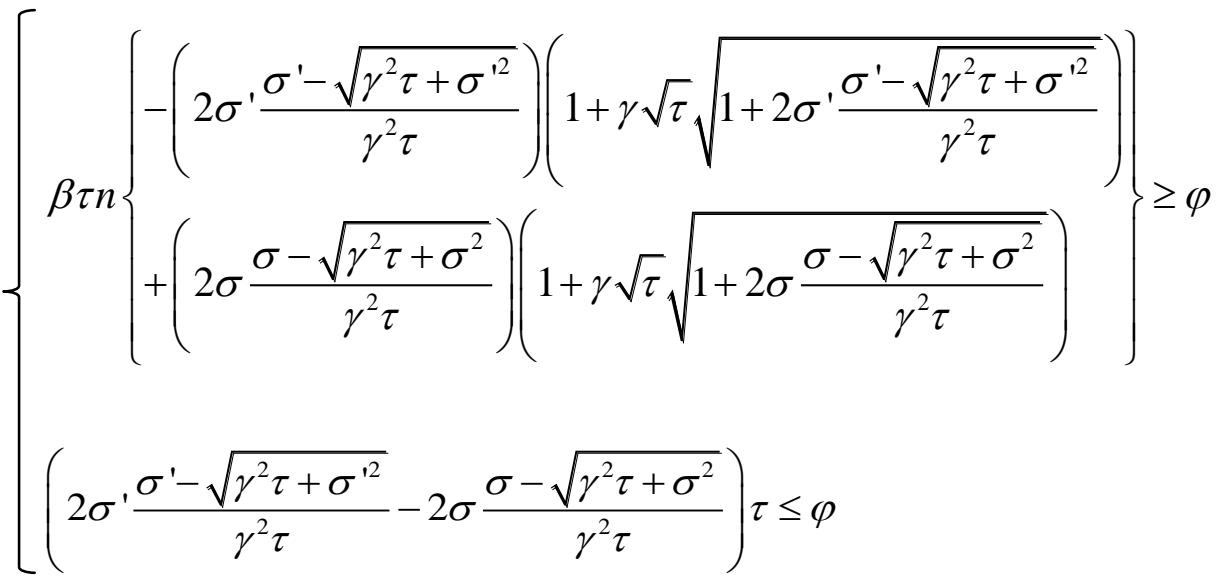


Therefore, there exists $\varphi$, which assumes the transition is possible if and only if the following inequality holds:

$$
\begin{aligned}
& \sigma^{\prime}\left\{\sigma^{\prime}-\sqrt{\gamma^{2} \tau+\sigma^{\prime 2}}\right\}\left[1+\beta n\left(1-\sigma^{\prime}+\sqrt{\gamma^{2} \tau+\sigma^{\prime 2}}\right)\right] \\
& \leq \sigma\left\{\sigma-\sqrt{\gamma^{2} \tau+\sigma^{2}}\right\}\left[1+\beta n\left(1-\sigma+\sqrt{\gamma^{2} \tau+\sigma^{2}}\right)\right]
\end{aligned}
$$

(i) Firstly, when positive value $\gamma$ is sufficiently small, (C-7) is approximated as follows by the Taylor expansion:

$$
\frac{1}{\sigma^{\prime}}+\frac{1}{\sigma} \leq \frac{2 \beta n}{1+\beta n}
$$

This condition is strict compared with that of the commitment assumption (transition is possible if $\left.\sigma>\sigma^{\prime}=\frac{1}{n \beta}\right)$.

(ii) Secondly, when positive value $\gamma$ is sufficiently large, (C-7) is approximated as follows by the Taylor expansion:

$$
\sigma^{\prime} \geq \sigma
$$

Therefore, transition is always impossible when positive value $\gamma$ is sufficiently large.

Note that, even in this case, the transition from voting system $\sigma$ to voting system $\sigma^{\prime}$ is possible if and only if both $\sigma$ and $\sigma^{\prime}$ are sufficiently large. Thus, Proposition 4 holds in this case, too. 


\section{Appendix 4}

Without specifying $\alpha$, the explicit solution of $\lambda$ with respect to $\sigma$ cannot be derived. Instead, we derive the relationship between $\lambda$ and $\sigma$. Since the result of Appendix 4 has already been proven in $\alpha=1$, we can assume $\alpha<1$ hereafter.

Lemma: The relationship $d \lambda / d \sigma<0$ holds.

Proof: Equation (10) and the political commitment assumption state the following relationship between $\lambda$ and $\sigma$.

$$
\lambda=\underset{\tilde{\lambda} \in[0,1]}{\arg \max }\left[(1-\tilde{\lambda})\left\{1+\gamma(\tau \tilde{\lambda})^{\alpha}\right\}+\sigma(1-\tilde{\lambda})\right]
$$

Let $f(\tilde{\lambda})$ be the maximand of (D-1), $(1-\tilde{\lambda})\left\{1+\gamma(\tau \tilde{\lambda})^{\alpha}\right\}+\sigma(1-\tilde{\lambda})$. Because $f(0)=1+\sigma$ is larger than $f(1)=0$, the derivative $f^{\prime}(+0)=+\infty$ when $\alpha<1$ and the continuity of $f, \lambda$ must be strictly larger than 0 and strictly less than 1 . Further, since $f^{\prime \prime}(\tilde{\lambda})$ is always negative for $f^{\prime \prime}(\tilde{\lambda})=\alpha \gamma \tau^{\alpha} \tilde{\lambda}^{\alpha-2}\{(\alpha-1)-(\alpha+1) \tilde{\lambda}\}, f(\tilde{\lambda})$ is hump-shaped with only one maximal, which coincides with the maximum. Thus, $\lambda$ must coincide with $\tilde{\lambda}$, which satisfies $f^{\prime}(\tilde{\lambda})=0$ and the following equation is satisfied through the unique solution of $\lambda$.

$$
-1+\alpha \gamma \tau^{\alpha} \lambda^{\alpha-1}-(\alpha+1) \gamma \tau^{\alpha} \lambda^{\alpha}-\sigma=0
$$

Let $g(\lambda)$ be $-1+\alpha \gamma \tau^{\alpha} \lambda^{\alpha-1}-(\alpha+1) \gamma \tau^{\alpha} \lambda^{\alpha}$. This is a decreasing function with respect to $\lambda$ since $g^{\prime}(\lambda)=\alpha \gamma \tau^{\alpha} \lambda^{\alpha-2}\{(\alpha-1)-(\alpha+1) \lambda\}<0$. Thus, since (D-2) is equivalent to $g(\lambda)=\sigma$, the derivative $d \lambda / d \sigma<0$ must hold.

Definition 2 is amplified to this universal case, with $\alpha<1$. Let $\lambda_{1}$ correspond to $\sigma_{1}$ and $\lambda_{2}$ correspond to $\sigma_{2}$ with $\sigma_{1}>\sigma_{2}$. Then, the transition from voting system $\sigma_{1}$ to voting 
system $\sigma_{2}$ is possible if and only if there exists a transfer variable $\varphi$ that satisfies the following conditions simultaneously:

$\left\{\begin{array}{l}\beta \tau n e_{t}\left[\left(1-\lambda_{2}\right)\left\{1+\gamma\left(\tau \lambda_{2}\right)^{\alpha}\right\}-\left(1-\lambda_{1}\right)\left\{1+\gamma\left(\tau \lambda_{1}\right)^{\alpha}\right\}\right] \geq \varphi e_{t} \\ \left(1-\lambda_{2}\right) \tau n e_{t}-\left(1-\lambda_{1}\right) \tau n e_{t} \geq-n \varphi e_{t}\end{array}\right.$

The above conditions are equivalent to the following condition:

$$
\left(1-\lambda_{2}\right)\left(1+\gamma\left(\tau \lambda_{2}\right)^{\alpha}\right)-\frac{\lambda_{2}}{\beta n} \geq\left(1-\lambda_{1}\right)\left(1+\gamma\left(\tau \lambda_{1}\right)^{\alpha}\right)-\frac{\lambda_{1}}{\beta n}
$$

Because of the inequality $\sigma_{1}>\sigma_{2}$ and the Lemma, an inequality $\lambda_{1}<\lambda_{2}$ holds.

Let $h(\lambda)$ be $(1-\lambda)\left(1+\gamma(\tau \lambda)^{\alpha}\right)-\frac{\lambda}{\beta n}$. Because $h(0)=1$ is larger than $h(1)=-\frac{1}{\beta n}$, the derivative $h(+0)=+\infty$ and the twice derivative $h^{\prime \prime}(\lambda)<0$ for $h^{\prime}(\lambda)=\alpha \gamma \tau^{\alpha} \lambda^{\alpha-2}\{(\alpha-1)-(\alpha+1) \lambda\}<0, h(\lambda)$ is a hump-shaped function. Then, the following conditions hold where $\bar{\lambda}$ is the unique maximizer for $h(\lambda)$.

(a) If the inequality $\lambda_{2} \leq \bar{\lambda}$ holds, the inequality $h\left(\lambda_{1}\right)<h\left(\lambda_{2}\right)$ always holds. Thus, in this case, (D-5) always holds.

(b) If the inequality $\lambda_{1}<\bar{\lambda}<\lambda_{2}$ holds, the inequality $h\left(\lambda_{1}\right)<h\left(\lambda_{2}\right)$ holds if and only if $\lambda_{2}$ is below a certain threshold. This threshold, $t\left(\lambda_{1}\right)$ can be given as a unique solution that satisfies $h\left(\lambda_{1}\right)=h\left(t\left(\lambda_{1}\right)\right)$ and $\bar{\lambda}>t\left(\lambda_{1}\right)$ simultaneously.

(c) If the inequality $\bar{\lambda} \leq \lambda_{1}$ holds, the inequality $h\left(\lambda_{1}\right)<h\left(\lambda_{2}\right)$ never holds.

In summary, the transition is possible if and only if both $\lambda_{1}$ and $\lambda_{2}$ are sufficiently small. That is to say, the transition is possible if and only if both $\sigma_{1}$ and $\sigma_{2}$ are sufficiently large. 


\section{References}

Alesina, A., Drazen, A., 1991. Why are stabilizations delayed? American Economic Review 81 (5), $1170-1188$.

Alesina, A., Perotti, R., Tavares, J., 1998. The political economy of fiscal adjustments. Brookings Papers on Economic Activity 1, 197-266.

Aoki, R., Vaithianathan, R., 2009. Is Demeny Voting the Answer to Low Fertility in Japan? Center of Intergenerational Studies Discussion Paper, No. 435.

Arrow, K., 1950. A difficulty in the theory of social welfare. Journal of Political Economy 58, $328-346$.

Ashibe, S., 2000. Constitutional Law III: Discussion of Human Rights (1) (augmented edition), Yuhikaku Publishing (in Japanese).

Bagehot, W., 1867. The English Constitution. United States: Cornell University Press.

Breyer, F., Craig, B., 1997. Voting on Social Security: Evidence from OECD Countries. European Journal of Political Economy 13 (4), 705-724.

Condorcet, M., 1785. Essai sur l'application de l'analyse à la probabilité des décisions rendues à la pluralité des voix, l'Imprimerie Royale, Paris (translation in English by McLean and Urken. 1995).

Crain, W. M., Tollison, R. D., 1993. Time inconsistency and fiscal policy: Empirical analysis of U.S. States, 1969-89. Journal of Public Economics 51, 153-159.

Cukierman, A., Meltzer, A., 1989. A political theory of government debt and deficits in a neo-Ricardian framework. American Economic Review 79, 713-732.

D’Amato, M., Galasso, V., 2010. Political intergenerational risk sharing. Journal of Public Economics 94, 628-637.

Demeny, P., 1986. Pronatalist policies in low-fertility countries: Patterns, performance and prospects. Population and Development Review 12, 335-358.

Foucault, M., Madies, T., Paty, S., 2008. Public spending interactions and local politics. Empirical evidence from French municipalities. Public Choice 137, 57-80. 
Hirazawa, M., Kitaura, K., Yakita, A., 2010, Aging, fertility, social security and political equilibrium. Journal of Population Economics 23 (2), 559-569.

Ihori, T., Doi, T., 1998. Economic Analysis of Japanese Politics. Bokutakusha (in Japanese).

Ihori, T., Itaya, J., 2001. A dynamic model of fiscal reconstruction. European Journal of Political Economy 17 (4), 779-797.

Kneebone, R. D., McKenzie, K. J., 2001. Electoral and partisan cycles in fiscal policy: An examination of Canadian Provinces. International Tax and Public Finance 8, 753-774.

Miwa, K., Kawashima, T., 2008. Vote-value disparity and seat allocation problems in the Upper House-clarifying key issues concerning the state of Japan and other countries. National Diet Library, Issue Brief Number 610 (in Japanese).

Oguro, K., Shimasawa, M., Aoki, R., Oshio, T., 2012. Demographic change, intergenerational altruism, and fiscal policy - A political economy approach. Studies in Applied Economics 6, forthcoming.

Ortega, G., 1961. The Revolt of the Masses. Translated from Spanish. London: George Allen \& Unwin Ltd.

Persson, T., Svensson, L. E. O., 1989. Why a stubborn conservative would run a deficit: Policy with time in consistent preferences. Quarterly Journal of Economics 104 (2), 325-345.

Persson, T., Tabellini, G., 2000. Political Economics: Explaining Economic Policy. United States: MIT Press.

Rogoff, K., 1990. Equilibrium political budget cycles. American Economic Review 80 (1), 21-36.

Romer, P., 1986. Increasing returns and long-run growth. Journal of Political Economy 94, 1002-1037.

Shi, M., Svensson, J., 2006. Political budget cycles: Do they differ across countries and why? Journal of Public Economics 90, 1367-1389.

Silke, U., 2004, Political Feasibility of Pension Reforms, The B.E. Journal of Economic Analysis \& Policy 4 (1), Article 20. 
Tabellini, G., 1990. A Positive Theory of Social Security, CEPR Discussion Papers 394, Centre for Economic Policy Research.

Tabellini, G., Alesina, A., 1990. Voting on the budget deficit. American Economic Review 80 (1), 37-49.Takeuchi, K., 2011. Representing children's needs in politics through an 'age-based voting system': reality through Demeny voting. Diet seat allocations based on youth. Nikkei Business (online, in Japanese). 